\title{
Solusi Persamaan Schrodinger dengan Menggunakan Metode Transformasi Diferensial
}

\author{
Muhammad Abdy ${ }^{1, \text { a) }}$, Hisyam Ihsan ${ }^{1, \text { b) }}$, dan Dhea Ayu Rossyana Dewi ${ }^{1, c)}$ \\ ${ }^{1}$ Jurusan Matematika FMIPA Universitas Negeri Makassar \\ a)muh.abdy@unm.ac.id \\ b)hisyamihsan@gmail.com \\ c)dhea.ayu.rd@gmail.com
}

\begin{abstract}
Abstrak. Penelitian ini membahas tentang solusi persamaan diferensial parsial linier yaitu persamaan Schrodinger. Solusi persamaan ini dilakukan dengan menggunakan metode transformasi diferensial yang merupakan metode semi-numerik-analitik yang dapat digunakan untuk menyelesaikan persamaan diferensial biasa ataupun persamaan diferensial parsial linier dan nonlinier. Metode transformasi diferensial merupakan metode yang menggunakan teori ekspansi deret pangkat pada bentuk transformasinya untuk menentukan solusi. Pada penelitian ini digunakan dua nilai awal pada persamaan Schrodinger yang diberikan. Solusi dengan kedua nilai awal yang diberikan diperoleh dengan menggunakan ekspansi deret Maclaurin. Kemudian solusi tersebut disimulasikan menggunakan software Maple18. Akibatnya, metode transformasi diferensial pada penelitian ini merupakan salah satu metode yang mampu menghasilkan solusi untuk persamaan Schrodinger.
\end{abstract}

Kata Kunci: Persamaan Schrodinger, Metode Transformasi Diferensial

\begin{abstract}
This study discusses the solution of linear partial differential equations, namely Schrodinger equation. The solution of the equation is done by using the differential transformation method which is a semi-numerical-analytical method, it can be used to solve both ordinary differential equations and linear or nonlinear partial differential equations. Differential transformation method is a method uses the theory of rank expansion in the form of transformation to determine solutions. In this study, two initial values in the given Schrodinger equation were used. Solutions with both initial values given are obtained using the Maclaurin series expansion. Then, the solution is simulated using Maple18 software. As a result, the differential transformation method in this study is one method that is able to solve a solution to the Schrodinger equation.
\end{abstract}

Keywords: Schrodinger Equation, Differential Transformation Method

\section{LATAR BELAKANG}

Salah satu bentuk permasalahan persamaan diferensial parsial linear adalah persamaan Schrodinger. Persamaan Schrodinger diperkenalkan oleh fisikawan Erwin Schrodinger pada tahun 1952 dan dijelaskan juga bagaimana hubungan antara ruang dan waktu pada sistem mekanika kuantum (Hakim \& Kusumastuti, 2012). Menurut Fitri (2015) dan Nayiroh (2011), 
persamaan Schrodinger diperiksa berdasarkan suatu gelombang monokromatik yang dapat dilihat dalam gambar sebagai berikut.

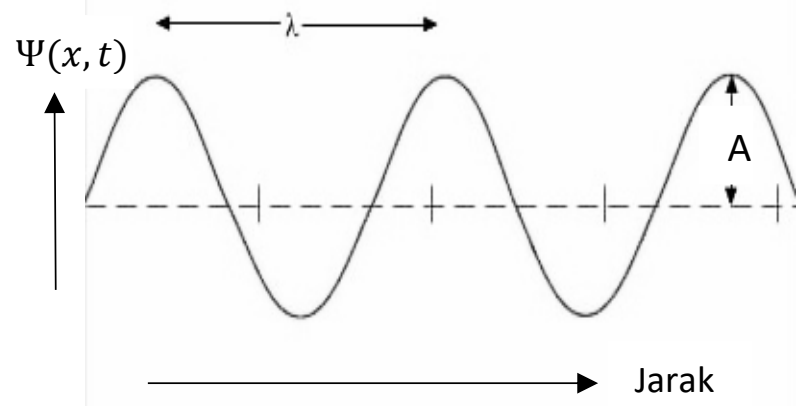

GAMBAR 1. Gelombang Monokromatik (KA, 2018)

dengan $A$ merupakan amplitudo dan $\lambda$ merupakan panjang gelombang. Gelombang monokromatik dapat dinyatakan dalam bentuk sebagai berikut

$$
\Psi(x, t)=A e^{-i \omega\left(t-\frac{x}{v}\right)}
$$

dimana $\omega$ merupakan frekuensi sudut dengan $\omega=2 \pi f, v$ merupakan kecepatan perambatan gelombang dengan $v=f \lambda$ dimana $f$ merupakan frekuensi gelombang dan $\lambda$ merupakan panjang gelombang (Siregar, 2018). Maka persamaan (1) menjadi

$$
\Psi(x, t)=A e^{i\left(\frac{2 \pi x}{\lambda}-\omega t\right)}
$$

misalkan $\lambda$ merupakan panjang gelombang dengan $\lambda=\frac{h}{p}$ dimana $h$ merupakan konstanta planck, $p$ merupakan jumlah gelombang dan diketahui $\bar{h}=\frac{h}{2 \pi}$ dimana $\bar{h}$ merupakan konstanta planck tereduksi maka diperoleh $h=\bar{h} 2 \pi$ dengan $k=\frac{p}{\bar{h}}$ (Siregar, 2018). Maka persamaan (2) menjadi

$$
\Psi(x, t)=A e^{i(k x-\omega t)}
$$

dengan menurunkan dua kali persamaan (3) terhadap $x$ serta menghubungkan dengan energi kinetik $E_{k}=\frac{p^{2}}{2 m}$ sedemikian sehingga menjadi

$$
-\frac{\bar{h}^{2}}{2 m} \frac{\partial^{2} \Psi(x, t)}{\partial x^{2}}=\frac{p^{2}}{2 m} \Psi(x, t)
$$

dengan menurunkan satu kali persamaan (3) terhadap $t$ maka dapat disederhanakan menjadi

$$
i \bar{h} \frac{\partial \Psi(x, t)}{\partial t}=E \Psi(x, t)
$$

Energi total merupakan penjumlahan dari energi kinetik $E_{k}$ dan energi potensial $E_{p}$ dimisalkan $V$ yaitu $E=E_{k}+E_{p}$ maka energi total menjadi $E=\frac{p^{2}}{2 m}+V$ sehingga persamaan (5) menjadi

$$
i \bar{h} \frac{\partial \Psi(x, t)}{\partial t}=\left(\frac{p^{2}}{2 m}+V\right) \Psi(x, t)
$$

dari persamaan (4) dan (6) diperoleh

$$
\begin{gathered}
i \bar{h} \frac{\partial \Psi(x, t)}{\partial t}=-\frac{\bar{h}^{2}}{2 m} \frac{\partial^{2} \Psi(x, t)}{\partial x^{2}}+V \Psi(x, t) \\
\Psi(x, 0)=g(x)
\end{gathered}
$$

Persamaan (7) adalah persamaan Schrodinger dengan kondisi awal persamaan (8).

Persamaan Schrodinger adalah gelombang sebagai representasi elektron sebagai partikel (Sudirham, 2013). Dalam sistem mekanika kuantum, gerak partikel dalam suatu sistem berkaitan dengan gerak partikel yang lain yang bersifat kompleks (Tan, 2016). Sehingga persamaan 
Schrodinger akan menggambarkan bagaimana pergerakan suatu partikel khususnya partikel elektron (Hakim \& Kusumastuti, 2012), serta kemungkinan keberadaannya partikel, tetapi persamaan Schrodinger tidak menentukan posisi partikel melainkan memberikan kemungkinan bahwa partikel akan ditemukan di sekitar posisi tertentu (Sudirham, 2013). Apabila sebuah fungsi gelombang memiliki nilai yang besar, maka semakin besar kemungkinan menemukan partikel pada posisi tersebut dan apabila memberikan nilai 0 ataupun memberikan nilai semakin kecil maka semakin kecil kemungkinan menemukan partikel pada posisi tersebut (Septyarin, 2014). Selain itu persamaan Schrodinger ini tidak mengatakan secara pasti bagaimana elektron bergerak sebagai fungsi waktu karena posisi dan momentum elektron dibatasi oleh prinsip ketidakapastian Heisenberg (Sudirham, 2013). Untuk menganalisa permasalahan tersebut, perlu mencari solusi penyelesaian dari persamaan Schrodinger.

Ada beberapa metode yang dapat digunakan dalam menyelesaikan persamaan Schrodinger, salah satunya ialah metode transformasi diferensial. Metode transformasi diferensial pertama kali diperkenalkan oleh Zhou untuk menyelesaikan persamaan diferensial baik linear maupun tak linear. Dengan menggunakan metode ini, persamaan diferensial parsial dan nilai awal yang diberikan ditransformasikan berdasarkan sifat-sifat transformasi diferensial dan tahapan yang dilakukan secara berulang-ulang untuk menghasilkan solusi dalam bentuk ekspansi deret Taylor dari fungsi analitik (Saadah, 2020). Beberapa sifat dari transformasi diferensial yang digunakan, yaitu sebagai berikut (Ayaz, 2003).

Sifat 1. Jika $\mathrm{w}(x, y)=u(x, y) \pm v(x, y)$ maka $\mathrm{W}(r, s)=U(r, s) \pm V(r, s)$.

Sifat 2. Jika $\mathrm{w}(x, y)=\alpha u(x, y)$ maka $\mathrm{W}(r, s)=\alpha U(r, s), \alpha$ konstanta.

Sifat 3. Jika $\mathrm{w}(x, y)=\frac{\partial u(x, y)}{\partial x}$ maka $\mathrm{W}(r, s)=(r+1) U(r+1, s)$

Sifat 4. Jika $\mathrm{w}(x, y)=\frac{\partial u(x, y)}{\partial y}$ maka $\mathrm{W}(r, s)=(s+1) U(r, s+1)$

Sifat 5. Jika $w(x, y)=\frac{\partial^{m+n} u(x, y)}{\partial x^{m} \partial y^{n}}$ maka

$$
W(k, h)=(r+1)(r+2) \ldots(r+m)(s+1)(s+2) \ldots(s+n) U(r+m, s+n)
$$

Beberapa peneliti telah mengkaji solusi persamaan Schrodinger dengan berbagai metode seperti yang telah dilakukan oleh Supardiyono (2009) meneliti tentang penyelesaian analisis numerik pada persamaan gelombang Schrodinger gayut waktu dengan metode Crank-Nicolson. Peneliti Dini Fitri (2015) meneliti tentang penggunaan metode analisis Homotopi pada penyelesaian persamaan Schrodinger-KdV. Beberapa peneliti menggunakan metode transformasi diferensial sebagai solusi dari persamaan diferensial biasa maupun persamaan diferensial parsial, misalnya Helliyatus Saadah (2020) yang mengkaji tentang solusi persamaan KDV (Kortewig De Vries) dengan menggunakan metode transformasi diferensial. Pada artikel ini akan membahas tentang analisis penyelesaian persamaan Schrodinger dengan menggunakan metode transformasi diferensial.

\section{HASIL DAN SIMULASI}

Persamaan Schrodinger yang akan diselesaikan dengan metode tranformasi diferensial yaitu pada persamaan (7) dengan persamaan (8) kondisi awal dari persamaan Schrodinger. Langkah pertama yaitu mentransformasikan persamaan (7) berdasarkan sifat sifat transformasi diferensial, sehingga transformasi dari persamaan Schrodinger dapat dilihat melalui Tabel 1. 
TABEL 1. Transformasi Persamaan Schrodinger

\section{Bentuk asal Bentuk Transformasi}

$$
\begin{array}{cc}
i \bar{h} \frac{\partial \Psi(x, t)}{\partial t} & i \bar{h}(s+1) U(r, s+1) \\
-\frac{\bar{h}^{2}}{2 m} \frac{\partial^{2} \Psi(x, t)}{\partial x^{2}} & -\frac{\bar{h}^{2}}{2 m}(r+2)(r+1) U(r+2, s) \\
V \Psi(x, t) & V U(r, s)
\end{array}
$$

Berdasarkan pada Tabel 1, persamaan (7) dapat dinyatakan sebagai berikut.

$$
U(r, s+1)=\frac{1}{i \bar{h}(s+1)}\left(-\frac{\bar{h}^{2}}{2 m}(r+2)(r+1) U(r+2, s)+V U(r, s)\right)
$$

Langkah kedua yaitu mentransformasikan persamaan nilai awal (8) sehingga menjadi

$$
U(r, 0)=\frac{1}{r !}\left[\frac{d^{r} g(x)}{d x^{r}}\right]_{x=0}
$$

Apabila disubstitusi $r=0,1,2,3, \ldots$ pada persamaan (10) maka diperoleh skema

$$
U(r, 0)=\frac{1}{r !} g^{(r)}(0)
$$

Langkah ketiga yaitu melakukan iterasi menggunakan persamaan (9) dengan mensubstitusikan nilai $U(r, 0)$ sehingga diperoleh beberapa bentuk skema yaitu

a. Untuk $r=0,1,2,3, \ldots$ dan $s=0$ maka diperoleh skema

$$
U(r, 1)=-\frac{\bar{h}}{i m} \frac{1}{2(r !)} g^{(r+2)}(0)+\frac{V}{i \bar{h}} \frac{1}{r !} f^{(r)}(0)
$$

b. Untuk $r=0,1,2,3, \ldots$ dan $s=1$ maka diperoleh skema

$$
U(r, 2)=\frac{1}{2 i \bar{h}}\left[\frac{\bar{h}^{3}}{i m^{2}} \frac{1}{4(k !) g^{(k+4)}(0)}-\frac{2 \bar{h} V}{i m} \frac{1}{2(k !)} g^{(k+2)}(0)+\frac{V^{2}}{i \bar{h}} \frac{1}{k !} g^{k}(0)\right]
$$

Dengan cara yang sama dapat diperoleh juga untuk $U(r, 3), U(r, 4), U(r, 5)$, dst.

Langkah keempat yaitu mensubstitusikan nilai yang telah diperoleh pada persamaan

$$
\Psi(x, t)=\sum_{r=0}^{\infty} \sum_{s=0}^{\infty} U(r, s) x^{r} t^{s}
$$

Sehingga diperoleh solusi dari persamaan Schrodinger yaitu

$$
\begin{gathered}
\Psi(x, t)=\sum_{r=0}^{\infty} g^{(r)}(0) x^{r} t^{0}+\sum_{r=0}^{\infty}\left(-\frac{\bar{h}}{i m} \frac{1}{2(r) !} g^{(r+2)}(0)+\right. \\
\left.\frac{V}{i \bar{h}} \frac{1}{r !} g^{(r)}(0)\right) x^{r} t+\sum_{r=0}^{\infty}\left(-\frac{\bar{h}}{2 i \bar{h}}\left[\frac{\bar{h}^{3}}{i m^{2}} \frac{1}{4(r !)} g^{(r+4)}(0)-\frac{2 \bar{h} V}{i m} \frac{1}{2(r !)} g^{(4)}(0)+\frac{V^{2}}{i \bar{h}} \frac{1}{r !} g^{\prime \prime}(0)\right]\right) x^{r} t^{2}+
\end{gathered}
$$

\section{Simulasi}

Selanjutnya akan dijelaskan salah satu contoh simulasi pada persamaan Schrodinger. Diberikan persamaan Schrodinger sebagai berikut:

$$
i \bar{h} \frac{\partial \Psi(x, t)}{\partial t}=-\frac{\bar{h}^{2}}{2 m} \frac{\partial^{2} \Psi(x, t)}{\partial x^{2}}+V \Psi(x, t)
$$


dengan kondisi awal,

$$
\Psi(x, 0)=6 x
$$

Masalah (16) dan (17) akan diselesaikan dengan menggunakan metode transformasi diferensial. Berdasarkan pembahasan sebelumnya, diketahui bahwa solusi persamaan Schrodinger dengan metode transformasi diferensial yaitu persamaan (15). Sehingga diperoleh solusi persamaan Schrodinger dengan kondisi awal persamaan (17) adalah

$$
\Psi(x, t)=6 x e^{\frac{v t}{i \bar{h}}}
$$

Dengan menggunakan aplikasi, diperoleh grafik 3D dan 2D dari solusi persamaan Schrodinger tersebut dengan parameter yang digunakan ialah $i$ bilangan imajiner, $\bar{h}=1.05457 \times 10^{-34} \mathrm{Js}$, dan saat $V=\{2,10,18\}$ dengan $-15 \leq x \leq 30$ dan $0 \leq t \leq 20$.

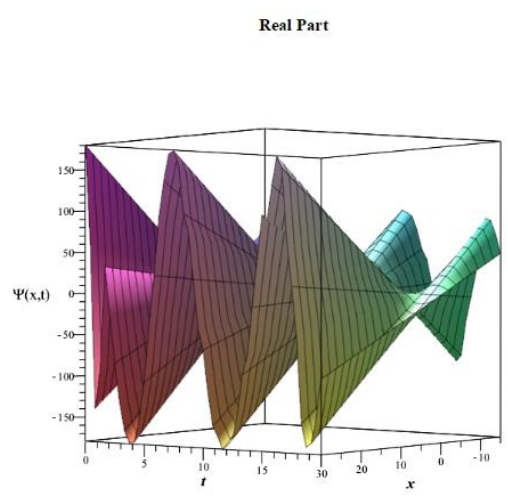

(a) $V=10 J$ 3D Part Real

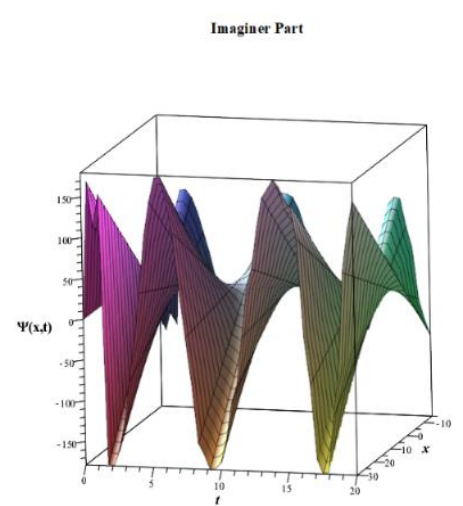

(c) $V=10 J$ 3D Part Imajiner

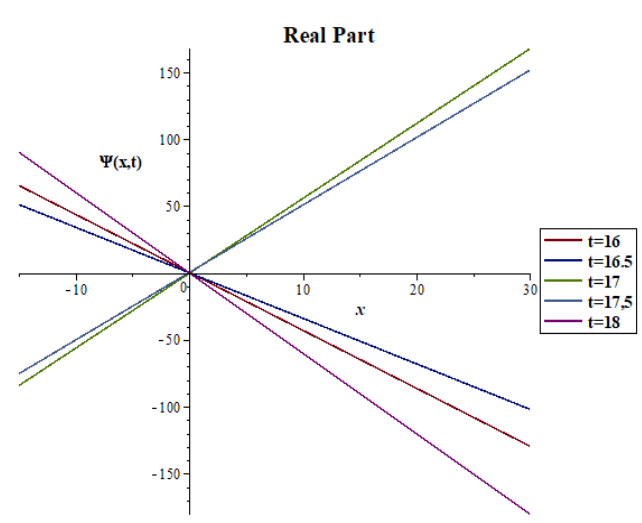

(b) $V=10 J$ 2D Part Real

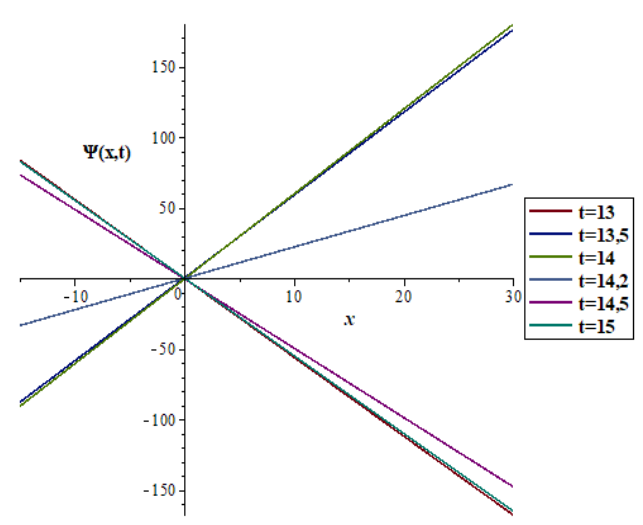

(d) $V=10 J$ 2D Part Imajiner 


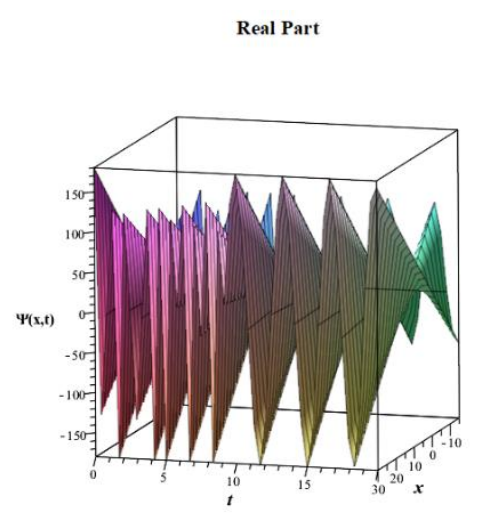

(e) $V=2 J$ 3D Part Real

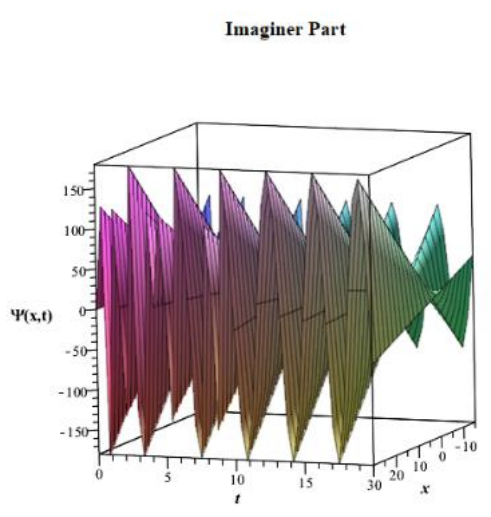

(g) ) $V=2 J$ 3D Part Imajiner

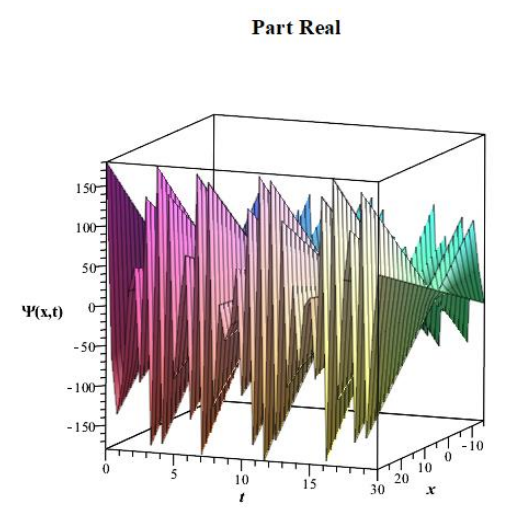

(i) $V=18 J$ 3D Part Real

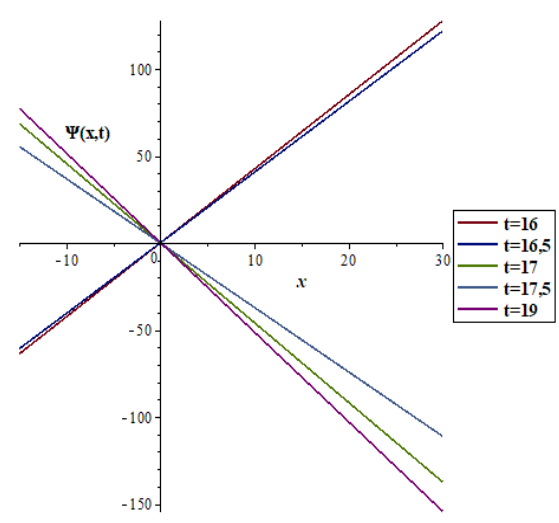

(f) $V=2 J$ 2D Part Real

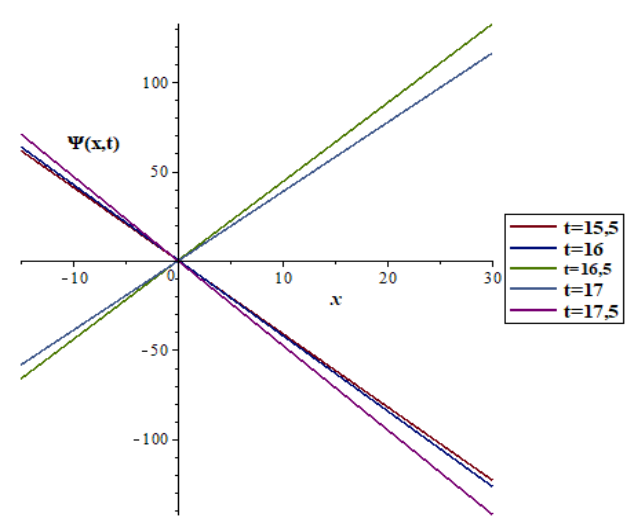

(h) $V=2 J$ 2D Part Imajiner

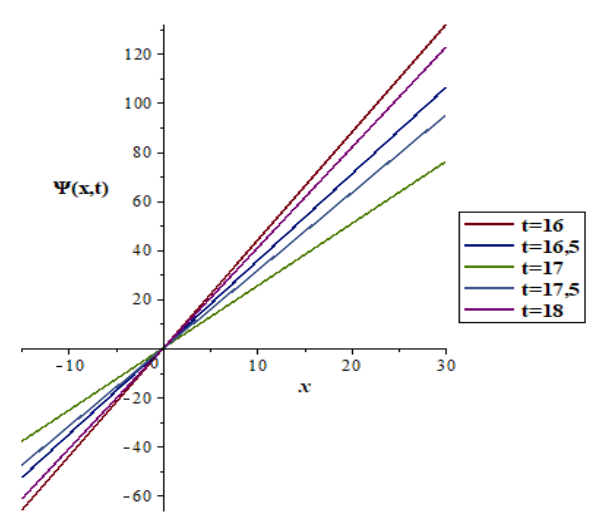

(j) $V=18 J$ 2D Part Real 


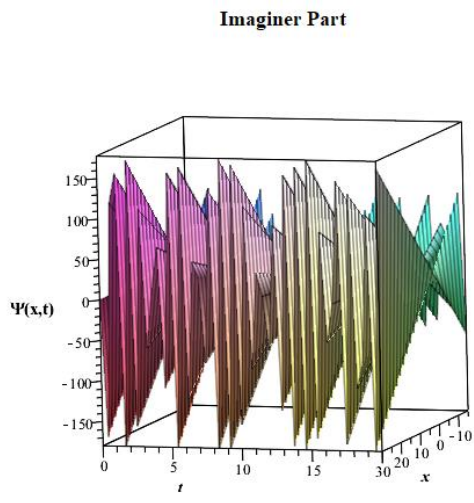

(k) $V=18 \mathrm{~J}$ 3D Part Imajiner

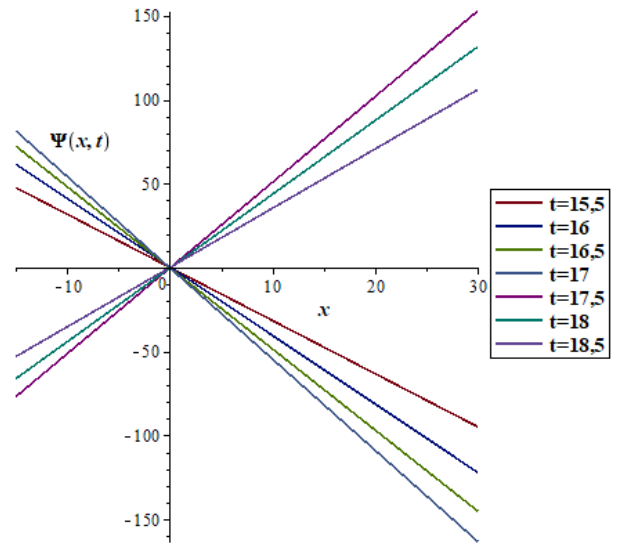

(1) $V=18 \mathrm{~J}$ 2D Part Imajiner

GAMBAR 2. Grafik Solusi Persamaan Schrodinger 2D dan 3D

Berdasarkan Gambar 2, dapat dikatakan bahwa dengan menaikkan dan menurunkan energi potensial $V$ yang digunakan diperoleh bahwa pada saat $28 \leq x \leq 30$ dan pada saat $13 \leq t \leq 18$ memiliki kemungkinan yang paling besar partikel berada pada posisi tersebut. Sedangkan pada saat $28 \leq x \leq 30$ dan pada $2 \leq t \leq 7$ memiliki kemungkinan yang paling kecil atau sangat tidak mungkin terdapat partikel pada posisi tersebut. Gambar 2 juga menunjukkan kemungkinan partikel berada pada posisi tertentu tidaklah daam selang waktu yang cukup panjang, dikarenakan hanya membutuhkan waktu yang singkat untuk partikel tersebut berpindah posisi. Sehingga pergerakan dari partikel pada real part maupun imaginer part tersebut sangatlah cepat berpindah. Dengan demikian, dari Gambar 2 dapat disimpulkan bahwa tidak ada perubahan signifikan pada grafik saat menaikkan ataupun menurunkan energi potensial $V$ yang digunakan.

Apabila agar solusi dari persamaan Schrodinger ingin memiliki arti fisis yang berarti tepat satu kemungkinan letak keberadaan partikel terdapat beberapa syarat yang harus dipenuhi. Akan tetapi, solusi (18) belum memnuhi persyarat fisis tersebut. Akibatnya kedua solusi diatas memiliki lebih dari satu kemungkinan keberadaan partikel. Sehingga tidak sebarang fungsi bisa dijadikan sebagai kondisi awal pada persamaan Schrodinger apabila ingin solusinya memiliki arti fisis.

\section{KESIMPULAN}

Melalui proses iterasi sederhana, solusi dari persamaan Schrodinger menggunakan metode transformasi diferensial diperoleh solusi analitik $\Psi(x, t)$. Solusi dari persamaan Schrodinger dengan menggunakan contoh kondisi awal, diperoleh dengan menggunakan ekspansi deret dan menghasilkan simulasi yang berarti bahwa kemungkinan partikel berada pada posisi tertentu tidaklah dalam selang waktu yang cuukup panjang, dikarenakan hanya membutuhkan waktu yang singkat untuk partikel tersebut berpindah posisi. Serta, solusi tersebut belum memnuhi persyaratan arti fisis sehingga kedua solusi belum memiliki arti fisis yang berarti terdapat lebih dari satu kemungkinan keberadaan partikel. 


\section{DAFTAR PUSTAKA}

Ayaz, F. (2003). On the two-dimensional differential transform method. Applied Mathematics and Computation, 143(2-3), 361-374.

Fitri, D. (2015). Penggunaan Metode Analisis Homotopi Pada Penyelesaian Persamaan Schrodinger-KdV (Skripsi). Institut Pertanian Bogor, Bogor.

Hakim, L., \& Kusumastuti, A. (2012). Generalisasi Fungsi Airy sebagai Solusi Analitik Persamaan Schrodinger Nonlinier. Cauchy, 2(2), 86.

KA, R. (2018). Sifat Gelombang Cahaya. Media Informasi Astronomi Indonesia. https://kafeastronomi.com/materi-3/sifat-gelombang-cahaya. Diakses pada 2 Februari 2021.

Nayiroh, N. (2011). Mekanika kuantum.

Saadah, H. (2020). Penyelesaian Persamaan KDV (Korteweig De Vries) Menggunakan Metode Transformasi Diferensial (Skripsi). Universitas Islam Negeri Maulana Malik Ibrahim Malang, Malang.

Septyarin, I. P. (2014). Fisika Modern (Mekanika Kuantum). Surabaya: Universitas Negeri Surabaya.

Siregar, R. E. (2018). Fisika kuantum. Jatinangor: Universitas Padjajaran.

Sudirham, S. (2013). Persamaan Gelombang Schrodinger. 1-8.

Supardiyono. (2009). Analisis Numerik Persamaan Gelombang Schrodinger Gayut Waktu dengan Metode Crank-Nicolson. Prosiding Seminar Nasional Penelitian, Pendidikan, Dan Penerapan MIPA (61-68). Yogyakarta, Indonesia: Universitas Negeri Yogyakarta.

Tan, H. (2016). Pendahuluan Persamaan Schrodinger. 617-643. 